\title{
Evil animes and Honorable Ruptures: Reading Gabriel García Márquez's Love in the Time of Cholera through a Public Health Humanities Lens
}

\author{
S. A. Larson ${ }^{1}$
}

Accepted: 30 September 2021 / Published online: 23 January 2022

(c) The Author(s), under exclusive licence to Springer Science+Business Media, LLC, part of Springer Nature 2021

\begin{abstract}
Extent health humanities readings of Gabriel García Márquez's Love in the Time of Cholera have focused on the doctor-patient relationship, the physician-scientist as a model for aspiring practitioners, and how individuals relate to the novel's health themes of death, disease, and disability. However, such medicine-focused readings neglect the population-level public health concerns of the novel as they relate to contagion, community, and quarantine. This paper contributes to the growing field of public health humanities by using a close reading method to explore how the competing endemic and epidemic public health issues shape the plot and metaphors of the novel.
\end{abstract}

Keywords Public Health Humanities · Parasites · WASH (Water Sanitation and Hygiene) Literature

\section{Introduction}

García Márquez's Love in the Time of Cholera is a darling of medical school humanities training. First published in Spanish in 1985 (with an English translation ${ }^{1}$ by Edith Grossman in 1988), the novel tells the story of a love triangle between Fermina Daza, Juvenal Urbino (Fermina's husband), and Florentino Ariza (a man obsessed with Fermina). Told in free indirect discourse, the story, organized through a series of flashbacks presented in nonlinear fashion, follows the lives of Fermina and Florentino from their initial childish infatuations, through their separation, to their eventual reconciliation in old age. Spanning a fiftyyear period between the late-nineteenth and mid-twentieth centuries, the novel explores themes including love, death, and aging. Set in an unnamed Latin American nation (most likely Colombia) on the Caribbean Coast, the novel also examines one's relationship to space and place as well as the deceptive nature of nostalgia.

Health humanities scholars have argued that because one of the novel's main characters, Juvenal Urbino, is a doctor, Love in the Time of Cholera not only provides practitioners

S. A. Larson

Stephaniealarson8@gmail.com

1 Bioethics Fellow, Cleveland, OH, USA 
and medical students with an entry point into the text but also valuable insights about good medical practice (Jones 1997; Clarfield 2007; Toledo-Pereyra 2008). The doctor figure of Juvenal, according to scholars such as Anne Hudson Jones, "is a doctor, a man of science and progress, who offers medical readers a familiar perspective as they enter this fictional world" $(1997,4)$. In other words, according to these readings of Love in the Time of Cholera, stories about doctors make good reading for doctors. Further, the novel, medical humanists have argued, also enters into issues relating to aging, death, and dying that are relevant to physicians. These themes have also been the focus of articles that argue for the novel's inclusion in medical education: budding doctors can learn what a good physician looks like by taking Juvenal as a model of aspirational practice.

Although Juvenal is a significant figure in the plot, this paper argues that Love in the Time of Cholera itself depends on population-level public health themes related to sanitation and contagious diseases to communicate the weight of relationships not only with other humans but with one's home. A public health humanities ${ }^{2}$ reading of the novel uncovers Juvenal's imperial approach to public health and challenges extent medical humanities conversations which frame his character as a model of medical practice. This reading of the novel adds to the extant health humanities scholarship on the text by performing a literary analytic reading in relation to its themes of public health. The larger goal of this paper is to demonstrate how a public health humanities approach can contribute to reflection and discussion in the health professions on questions related to history, culture, attribution for behavior, power, and representation.

\section{Diseased nostalgia and hygienic privilege}

In García Márquez's novel, memory and the deception of nostalgia are significant themes. Whether the memory is of a lover or one's homeland, characters in the novel are often guilty of idealizing a past that was anything but ideal. According to the narrator's own reflection on Juvenal's nostalgia as a young man, "the heart's memory eliminates the bad and magnifies the good, and . . . thanks to this artifice we manage to endure the burden of the past" (106). The shuttering of the bad and magnification of the good is illustrated in the physical landscape of Juvenal's unnamed home. Beneath his idealized memory of his home are the stench, filth, and disease left by the legacy of Spanish colonialism.

During his investigation of his friend's, Jeremiah de Saint-Amour's, suicide, Juvenal ventures into the "old slave quarter" to meet with the dead man's secret multiracial mistress (12). It is a "death trap of the poor" that challenges Juvenal's idealized "maniacal love" for his "colonial city" $(12 ; 16)$. The narrator notes that when faced with the reality of the old slave quarter's grim conditions, Urbino finds that "the pestilence so frequently idealized by nostalgia became an unbearable reality" (12).

The old slave quarter is not Juvenal's natural haunt. As an eminent physician, he lives among and serves the wealthy. The narrator notes that "he was always an expensive and exclusive doctor, and his patients were concentrated in the ancestral homes in the District of the Viceroys" (10). Juvenal's home provides a structural description of his own place in the social structure of the city. His house is large and airy: "One-story, spacious and cool, it had a portico with Doric columns on the outside terrace" (18). The house also resembles a past long gone. According to the narrator, the "house stood in another time" (18).

This home lost in the past suits Juvenal who, himself, seems to resist the present by dressing in the formal style of his youth and maintaining an ornate carriage long after such 
a mode of transportation has fallen out of fashion. However, amidst the sprawling, old fashioned beauty, the home "commanded a view of the still, miasmic water and the debris from sunken ships in the bay" (18). Juvenal's home faces the disease-carrying, polluted water, but does so from a distance. Likewise, Juvenal sees the poor, filth, decay, and contagion of his homeland from a reasonable distance. He, as this paper discusses later, "commanded a view" of the poor areas that are outbreak hotspots, directing public health policy and infrastructure, without immersing himself in the poor areas like the old slave quarters.

Part of Juvenal's aversion to working with the poor may be linked to his position of hygienic privilege. Juvenal is a hygienically-oriented figure, so much so that his bathroom is part of his character. The narrator introduces his character by providing detail about his access to and daily interactions with bathroom amenities. He battles the toilet in old age and replaces his European tub. This means that Juvenal has indoor plumbing, a luxury, perhaps imported from his training in Paris where the cholera outbreak led to the redevelopment of the city's water, sanitation, and hygiene (La Berge 2002). He also has a shower because he does not find a tub sanitary enough. Juvenal lives in such a position of sanitary privilege that one of his most significant arguments with his wife involves distributing blame regarding the failure to replace soap in the bathroom (28-30). His maintenance of a sanitary home makes his visit to the old slave quarter all the more horrifying.

While Juvenal extends philanthropy to the poor, he does so at a generous distance, which renders the old slave quarter a foreign landscape for him. When de Saint-Amour's suicide letter leads Juvenal to the old slave quarter, the narrator describes the decision as "so foreign to [Juvenal's] usual habits that his coachman wanted to make certain there was no mistake" (11). The foreignness of the slave quarter is further underscored by the fact that Juvenal and his coachman get lost and "had to make many turns and to stop to ask directions several times in order to find the house" (12). Juvenal constitutes the antithesis of disease so that areas made hospitable to outbreaks are foreign. This association creates a contrast between him and another protagonist, Florentino, who seems to be the site of emotion materialized as disease.

The old slave quarter translates social hierarchies into physical conditions that lead to the ill health of the individuals who live there:

In winter sudden devastating downpours flooded the latrines and turned the streets into sickening bogs. In summer an invisible dust as harsh as red-hot chalk was blown into even the best-protected corners of the imagination by mad winds that took the roofs off the houses and carried away children through the air. (17)

No season provides respite for the people of the old slave quarter, every day an assault not only on the scant shanties they occupy but also on their bodies. The old slave quarter, for Juvenal, is the accumulation of the colonial abject: the poor, the formerly enslaved, and mixed-race people (17). These identity markers are then conflated with the fact that the old slave quarter literally holds the city's waste.

The area's poor public health is the byproduct of Spanish colonial rule: "most of [the shanties] rested on pilings to protect them from the flooding of the open sewers that had been inherited from the Spaniards" (12). Imperial public health efforts, as evidenced by the waste flooding the street, have only worked to exacerbate the problem of disease in the old slave quarter. Rather than being a disease of the poor (as Juvenal's point of view seems to suggest), parasitic infections and other endemic diseases were "a sickness of ecological, economic, and cultural displacement and recombination" (Palmer and Molina 2004, 679). The narrator is signaling a grim morbidity rampant in the old slave quarter that, for Juvenal, is a disease of poverty and race, which is at odds with the historical perception that 
recognizes the larger sociological (i.e., colonial) forces that have shaped the endemic and epidemic landscape that run rampant in the streets.

Juvenal's encounter with his friend's lover involves a discussion of de Saint-Amour's decision to take his own life before he reaches old age, how his lover facilitated his suicide, and how she decided to live the remainder of her life without drowning in grief (a response Juvenal views as heinous). ${ }^{3}$ Significantly, this encounter ends with Juvenal's repudiation of the woman: "Dr. Urbino already realized how completely he would repudiate the memory of that irredeemable woman: only a person without principle could be so complaisant toward grief" (16). De Saint-Amour's lover is never named (by either Juvenal or the narrator). Like his magnificent home, which faces but never directly acknowledges the miasmic and dire conditions of the poor, Juvenal himself keeps the poor in the periphery of his care and concern as a citizen and physician. The vague language of "thought" here signals that there is more to his repudiation. He also repudiates the memory of the old slave quarter that signals the failure of his public health philanthropy.

\section{Neocolonialism and public health}

As a young man, Juvenal studied medicine in Paris. Throughout the novel, the narrator refers to Juvenal with his official title, Dr. Urbino, which inextricably links the character to his medical practice and authority. In the section in which the narrator recounts his return from medical training in Paris, the narrator refers to Juvenal as Dr. Juvenal Urbino, further establishing his medical practice while underscoring Juvenal's desire to develop his own identity, practice, and medical authority separate from his father, Dr. Marco Aurelio Urbino. As an old man, Juvenal maintains a specific image of an educated, Western medical practitioner. The narrator describes his "carefully combed back [hair]" and a "Pasteur beard, the color of mother-of-pearl" which were "faithful expressions of his character" (4-5). Juvenal not only attempts to emulate Western scientists and doctors in his practice but also to embody the presence and authority of a figure like Pasteur. His carefully cultivated image also involves a "too obvious display of learning and the disingenuous manner in which he used the power of his name," which carries with it the authority of his wellrespected physician father (5). In this section, the narrator reverts to Juvenal's name without his title to signal a time shift to Juvenal's childhood memories.

The novel foreshadows Juvenal's experience in the old slave quarter by showing how he responded to his homeland when he returned from his medical training in Paris. He returns with an ideal vision of his home, but the moment the ship reaches his homeland's port, his memory is shattered by "the unmerciful reality that came pouring in through the window" (106). The reality of Juvenal's flawed city is communicated through its dire public health situation. Upon his return from Paris, Juvenal finds it "impossible to discern the ardent scent of jasmine behind the vapors of death from the open sewers" (106). The putridity of the city overwhelms the body. If one closes off one sense, such as sight, one will still be overwhelmed by another sense, like smell. Juvenal takes the role of the outsider, coming in to "impose" his will without consideration of the cultural aspects of health (108). He does not attempt to understand the culture or healing traditions of the people who are the targets of his public health efforts. His tactics are as imperially grounded as the open sewers that remain from the Spanish colonial rule.

At the start of the novel, Juvenal is presented as an eminent figure, a patron of the arts, sciences, and his community. The narrator even notes: "He organized the construction of 
the first aqueduct, the first sewer system, and the covered public market that permitted filth to be cleaned out of Los Animas Bay" (43). The material reality of the dire conditions in the old slave quarter challenges Juvenal's luminary image in the collective memory of the community. As the narrator shows, one's memory of a person, like one's memory of a homeland, is also subject to an overly positive idealization. For example, after returning from Paris, Juvenal researches his own father's efforts to fight cholera while the young doctor was away in Paris. He learns that his father's methods for combating cholera, "had been more charitable than scientific and, in many ways, contrary to reason, so that in large measure it had fostered the voraciousness of the plague" (112).

Juvenal's father was "a civic hero" who "personally designed and directed public health measures" much as his son does (112). One can imagine Juvenal's father was equally assured of his reasoning and approach to public health, just as his son is after his return from Paris. Yet, in retrospect, Juvenal's father's work may have exacerbated the cholera outbreak. Juvenal's discovery challenges his own methods and belief that his approach is the soundest way to combat public health plagues/contagion. The narrator, who has access to the past and future, presents evidence that Juvenal may be subject to the same fickle community memory. When the doctor dies, an artist memorializes Juvenal as a hero, a marked contrast to the reality of his death, which involves Juvenal falling half-dressed from a ladder. The portrait is hung in the hallowed halls of the institutions Juvenal patronized, and, according to the narrator, remains until the memory of Juvenal changes and instead his image, captured in the painting, becomes "a symbol of an aesthetic and a time they despised" (46). Thus, despite the narrator's account of Juvenal as a hero of public health, much of this image may be mere nostalgia, which is subject to the ever-stepping march of time and change of public opinion.

When working with the Misericordia Hospital of his homeland upon returning from Paris, Juvenal finds "the antiquated house of health as stubborn in its attachment to atavistic superstitions" (108). According to his point of view, there is wrong medicine (the cultural folk healing of his Latin American homeland) and right medicine (Western). Despite Juvenal's self-assurance, he meets with dissenters. The narrator, who previously provided Juvenal's critique of his fellow practitioners, then provides external perception of his forceful interventions from the point of view of his critics:

He was in conflict with everything: his renovating spirit, his maniacal sense of civic duty, his slow humor in a land of immortal pranksters - everything, in fact, that constituted his most estimable virtues provoked the resentment of his older colleagues and the sly jokes of younger ones (108)

What he sees as obvious need to help his homeland may be mistaken for forcing a certain type of medical care and public health practice onto the people. While Juvenal sees only filth, disease, and decay, the people of his home "spent their lives proclaiming their proud origins, the historic merits of the city, the value of its relics, its heroism, its beauty" (111). The insight the narrator provides into Juvenal's mind shows he believes the people are "blind to the decay of the years" and that only Juvenal "loved [his homeland] enough to see it with the eyes of truth" (111). This contrast between uncritical love and recognition of nostalgia's trappings is highlighted in the larger symbolic interaction of Juvenal's attempts to clear the water of animes.

When Juvenal returns from medical training in Paris, "His obsession was the dangerous lack of sanitation in the city" (108). He approaches public health as a combination of infrastructure and personal responsibility. For infrastructure, "he appealed to the highest authorities to fill in the Spanish sewers that were an immense breeding ground for rats, 
and to build in their place a closed sewage system whose contents would not empty into the cove at the market, as had always been the case, but into some distant drainage area instead" (109). The open sewer system demarcates economic divides among the city since "the well-equipped colonial houses had latrines with septic tanks, but two thirds of the population lived in shanties at the edge of the swamps and relieved themselves in the open air" (109). Feces threatens to literally coat the inhabitants of the city. Instead of a city drowned in memories, Juvenal sees a city buried beneath feces. Perhaps most significant of all, the excrement would be crossing social hierarchies.

Given that the rich have their own successful sanitation system, only the poor are guilty of open-air defecation in which "excrement dried in the sun, turned to dust, and was inhaled by everyone along with the joys of Christmas in the cool, gentle breezes of December" (109). The waste of the poor becomes the inescapable air that the rich have to breathe. In terms of personal responsibility, "Dr. Juvenal attempted to force the City Council to impose an obligatory training course so that the poor could learn how to build their own latrines" (109). For him, open air defecation is an issue of personal responsibility, like his encounter with the toilet in old age. The larger social and cultural factors, he believes, can be mitigated by training. Juvenal also "fought in vain to stop them from tossing garbage into the mangrove thickets that over the centuries had become swamps of putrefaction, and to have them collect it instead at least twice a week and incinerate it in some uninhabited area" (109). Notably, the narrator uses the language of effort rather than the language of success to describe Juvenal's public health policy and infrastructure. He "attempted" and "fought in vain" (109). According to the narrator's descriptions of the old slave quarter when Juvenal is an old man, his efforts to reform poor areas failed. The old slave quarter is still filthy and has old open sewers.

Juvenal also attempts to reform the old underground cistern system. This system is preferred by the people because it produces "crystalline and cool" water that "tasted of the forest" (109). The water is a metaphor for vision that runs throughout the novel to characterize one's relationship with a lover (such as Fermina and Florentino) or the land (as is the case with Juvenal and his home). While the people see only pure water, "Dr. Juvenal Urbino was not taken by these appearances of purity, for he knew that despite all precautions, the bottom of each earthen jar was a sanctuary for waterworms" (109). The waterworms, according to Juvenal, cause painful and sometimes deadly orchitis (scrotal swelling).

Contrary to Juvenal's assessment, the locals link water from the underground cistern system with "honorable ruptures" caused by mythic animes, which are described as "supernatural creatures who, from the sediment in still water, courted young maidens and could inflict furious vengeance because of love" (110). The animes are gender-specific creatures that infect men and cause their hosts to pursue and torment women. In this case, the creatures are blamed for violence when women rebuff the advances of men, as is the case of a school teacher whose home was stoned. While men view the infection as honorable, one can imagine women, like the teacher, may find the animes a mere extension of patriarchal culture in which women must submit to the will of men or else face threats of violence.

As a child, prior to his training in Paris, Juvenal subscribed, reluctantly, to the myth of the animes. The narrator records Juvenal's transition from a mythic to a scientific view of the creatures in the water: "And so it was a long while before he learned that waterworms were in reality the larvae of mosquitoes, but once he learned it he never forgot it, because from that moment on he realized that they and many other evil animes could pass through our simple stone filters intact" (110). The worms transform themselves from supernatural creatures in Juvenal's life to simple parasites. His perspective changes when he adopts a new, Western, narrative frame. Yet the people of his hometown maintain the mythical quality of the animes: "For a long time the water in the cisterns had been honored as the cause of the scrotal hernia 
that so many men in the city endured not only without embarrassment but with a certain patriotic insolence" (110). Parasites are a point of pride connected with masculinity. What he sees as the horrifying symptoms of a disease, the people read as a gift from the earth:

[Juvenal] could not avoid a spasm of horror at the sight of men with ruptures sitting in their doorways on hot afternoons, fanning their enormous testicle as if it were a child sleeping between their legs [ . . .] well-carried rupture was, more than anything else, a display of masculine honor. (110)

While the creature is never named, the anime, in terms of parasitology, is more than likely the filarial nematode. Juvenal's discussion of the animes as worms that live in untreated water and spread through mosquito larvae characterize filarial nematodes. Filarial nematodes can cause the "honorable rupture" which, in parasitic parlance, is referred to as orchitis, or swollen scrotum. Yet the men do not conceive of their condition as the product of a parasitic infection. The water, which contains the animes, is "honored," and those who develop the orchitis do so "not only without embarrassment but with a certain patriotic insolence" (110). The animes are inextricably linked with the land, and one's development of "ruptures" is a gift from the land, something one can wear with pride and a certain amount of arrogance. Likewise, the animes are something to nurture, described like children. This conceptualization of the animes offers a direct contrast to public health narratives surrounding parasites such as hookworm, malaria, and filarial nematodes. The parasite is a gift, one that is nurtured in the body. The men and their animes present an alternative parasite narrative that challenges Western public health ideology that was being transported across the globe through philanthropic projects like the Rockefeller Foundation in the early twentieth century (Ettling 2000).

One may turn to a 1900 article on filarial parasites that was published in two separate newspapers in the United States-first in St. Louis and then, shortly afterward, in San Francisco- to see a contrasting narrative between Western public health and community conceptions of parasitic infection in the global south ("Strange Case" 1900). The article entitled "The Strange Case of a Man who had Snakes in His Blood" depicts filariasis as both abnormal, something to be studied, and a horrific monster. The article opens by underscoring the nightmare nature of filarial nematodes by calling them "Snakes in his blood!" ("The Strange Case" 1900). One can visualize this nightmare through microscopy, which will reveal that the blood is "alive with great writhing, wriggling serpents" ("The Strange Case" 1900). These parasites are "sinuous and twisting things, made monstrous and repulsive under the lenses" and destroying the host from the inside out by "devouring a blood corpuscle" ("The Strange Case" 1900).

Positioned as "serpents" in one's blood, the filarial nematodes are already horrific, leaving the reader with a creepy crawly feeling. However, this horror is enhanced by the magnification of scientific technology. Visualizing the otherwise indivisible parasite makes it "monstrous and repulsive." By describing the nematode as a snake, the author draws upon Western Christian associations of serpents as creatures of evil including original sin. The U.S. public health narrative of filariasis, like that of hookworm, depended on a narrative of horror and shock, with one paper calling it a "microscopic maggot" ("Popular Science" 1909). Maggots are not parasites, but rather larvae of flies that feast upon decaying matter. By comparing the filarial nematode with a maggot, the author is developing a horrifying link, one which claims, incorrectly, that the individual carrier of the parasite is decaying from the inside. Notably, this decay is blamed on the parasitic hosts themselves. In the snake blood article, the author notes: "The laboring people either through ignorance or careless disregard of the dangers that lurk in this surface water frequently 
drink it" ("The Strange Case" 1900). It is through this rhetoric of parasitic invasion and individual accountability that Juvenal approaches the animes. His European training has shown him the "scientific fallacy" of community beliefs (110). However, because these beliefs are entrenched in "local superstition," it is difficult to convince the public that the honorable ruptures are really a deadly parasitic infection (110).

Juvenal positions himself as the savior of his community, bringing his Paris training and knowledge to his Latin American home, imagining he is the only one who can truly see the filth under the nostalgia. He remarks, "How noble this city must be for we have spent four hundred years trying to finish it off and we will still have not succeeded" (111). Yet ultimately, Juvenal's work is dependent on constructs of race and class as well as a dichotomy between Western public health/medical practices and community folk beliefs. His failure to reform the old slave quarter, and his aversion as an old man visiting the area, belies his own split image; a pillar of his community, the idealized physician fighting disease and corruption, but ultimately only effecting change in the upper crust of society. One is left to wonder about the extent to which Juvenal influenced the decline of cholera in the city. The narrator notes that "no one doubted that the sanitary rigor of Dr. Juvenal Urbino, more than the efficacy of his pronouncements, had made the miracle possible. From the nineteenth into the present century, cholera was endemic not only in the city but along most of the Caribbean coast and the valley of the Magdalena, but it never again flared into an epidemic" (115). However, the narrator reports that the cholera outbreak "ended as suddenly as it had begun" (112). The narrator notes that "[cholera] had no regard for color or background" (112). While cholera may not "regard" race or background, the hierarchical structures of Juvenal's homeland create environments that foster the spread of deadly epidemics, such as the open sewers and shanties of the old slave quarter, which means that "the cholera was much more devastating to the black population, which was larger and poorer" (112). The narrator further emphasizes the social factors involved in the spread of cholera by repeating that "cases until that time had occurred in the poor neighborhoods, and almost all of those among the black population" (116). The narrator is describing cholera as the product of racism and poverty. Juvenal's efforts to institute sanitary reform are rooted in his desire to prevent the spread of epidemics from poor neighborhoods to the upper crust of his society. While racist and classist structures and systems have made vulnerable poor, Black neighborhoods in the wake of an epidemic, cholera, as depicted in García Márquez's work, does not respect class boundaries. Stopping the potential for outbreaks in one part of a community (that of the poor) is much less an effort to help the target community than it is to help the surrounding communities (those of the rich).

\section{Metaphors of quarantine}

Ironically, despite his fears of aging and death, Juvenal ends his life on a ladder while attempting to catch his beloved parrot. This is the second death in the novel and opens space for Juvenal's wife, Fermina Daza, and her suitor from childhood, Florentino Ariza, to be re-introduced. Florentino and Fermina engaged in an innocent childhood crush that was eventually broken up by Fermina's father, who takes her away, across dangerous revolutionary lines, to stay with family. Although Juvenal marries Fermina (who is from a lower socioeconomic status than he), his true relationship is with his city. He conceives of his love for Fermina as the "result of a clinical error" that occurred when "all his reserves of passion were concentrated on the destiny of his city which, he said, with great frequency and no second thoughts, had no equal in the world" (105). Just as Juvenal is disillusioned 
in his love for his city after his time away in Paris, Fermina experiences a similar lifting of her illusory veil of love for Florentino when she returns from the exile imposed upon her by her father. In the market, she returns not to find her idealized love but rather living death and the embodiment of disease, "those other glacial eyes, that livid face, those lips petrified with fear" which cause her to feel "the abyss of disenchantment" (102).

Florentino is the city - with its public health problems and epidemics - incarnate. Florentino is naturally sickly: "Aside from his defective vision, he suffered from chronic constipation, which forced him to take enemas throughout his life" (54). As a child, Florentino's physician, who is also a relative, shares his constipation-based philosophy about people: "The world is divided into those who can shit and those who cannot" (183). Florentino belongs to the latter category. His inability to give up his childish love for Fermina results in a type of emotional blockage. Even though Fermina rejects him after becoming disillusioned, Florentino refuses to move on with his life. After Fermina breaks up with him, Florentino has his first sexual encounter-a rape by a woman he can never identify. After this initial event, Florentino begins a series of superficial sexual relationships (a total of 622 affairs), largely with widows in order to avoid any emotional intimacy. He mires in a state of emotional stagnation and physical preservation in the hope that he and Fermina can be together after her husband dies.

Juvenal and Florentino function as opposing entities. Juvenal's love for his city is expressed in attempts to stop the spread of the cholera epidemic. Motivated by the death of his physician father from cholera, the disease "became an obsession for him" (114). Juvenal meets Fermina Daza when one of his physician friends mistakes her symptoms for cholera (115-116). Juvenal's first interaction with Fermina is clinical and focused on detecting and, if diagnosed, treating cholera before it spreads: "he had eyes only for the slightest hint that she might be a victim of the plague" (117).

Florentino experiences love by expressing the symptoms of cholera. When he first meets and becomes infatuated with Fermina, Florentino does not do so with the clinical detachment of Juvenal but instead physiologically expresses his emotion through the expulsion of "diarrhea and green vomit" as well as symptoms such as dizziness and fainting, which his mother believes "did not resemble the turmoil of love so much as the devastation of cholera" (61). Florentino's mother calls a doctor, who examines him and discovers that while he has the "weak pulse, the hoarse breathing, and the pale perspiration of a dying man," he only has "the symptoms of love" which "were the same as those of cholera" (61).

Florentino becomes inextricably linked with a metaphoric cholera (the very disease Juvenal attempts to eradicate), so much so that his mother maintains that "the only disease my son ever had was cholera," about which, the narrator notes, "She had confused cholera with love, of course" (218). That final "of course" signals a matter-of-fact sense to the matter, as though the signs and symptoms of cholera and love are impossible to disentangle, and such knowledge is widely shared. As though to further develop the cholera metaphor, Florentino, in his youthful courting of Fermina, is "desperate to infect her with his own madness" (69). Like the disease, love and its symptoms themselves are contagious. And, as suggested through his association with cholera, Florentino is contagious to the most vulnerable. Florentino's niece and legal ward, América Vicuña, is warned "not to spend more time with her guardian than necessary, not to eat anything he had tasted, and not to put her face too close to his, for old age was contagious" (273). This warning proves true. Florentino engages in a sexual relationship with the girl, who is only fourteen when he is in his eighties. When Florentino leaves América for his chance to be with Fermina after the death of Juvenal, the girl, once a promising scholarship student studying to become a teacher, begins to slip in her schoolwork until she finally commits suicide. In the novel, the natural progression of age is death, and although América is only fourteen, she takes on Florentino's association with age and death, ending her own life. 
Parasites may be material (as in infectious entities that are a public health threat) or mythical, as in the case of the animes/waterworms. Florentino's character develops a third use of parasites: as sources of metaphor. Florentino uses the image of the parasite to describe the widows who enable the bulk of his sexual experiences. After the deaths of their husbands, Florentino finds them "living like parasites of gloom in their big empty houses" (202). These women, according to Florentino, feed on the sadness that results from the death of their husbands. Ironically, Florentino himself is a "parasite of doom," one who worms his way into Fermina's life, engaging in a period of latency for over fifty years in which he never interacts with Fermina, and finally emerging at the opportune moment when Fermina becomes a widow.

Even Florentino's appearance is worm-like: he is a small, slight, myopic, balding man without teeth. This metaphoric parasite is distinct from the mythic (and honorable) or material (and destructive) and instead presents a way to describe relationships. When Florentino renews his love for Fermina after the death of her husband, she is, understandably, frustrated and rebuffs him. However, after maintaining himself for nearly fifty years for her, Florentino persists, continuing to court her against her will until, finally, she begins to cave in and agrees to take a cruise with him.

As the novel concludes, Fermina and Florentino renew and consummate their relationship aboard a ship. Ships, earlier in the novel, bring individuals into contact with plague and disease both as vessels that transport disease (through transportation of goods and people) and contain it (through quarantine). As a young man, Florentino takes his first and only trip aboard a ship in order to avoid Fermina's impending wedding. While on the ship, Florentino, unable to forget his love for Fermina, begins to exhibit love symptoms that are mistaken for cholera which leads the Captain to fly the plague flag and the ship's doctor to quarantine and treat Florentino (147). The boat is likewise a microcosm for disease with its "suffocating toilets on the passenger deck," heat, mosquitoes, and "pestilential stench" of rotten meat and waste (139-141).

Maritime quarantine was a way to prevent the spread of contagious diseases, like cholera, across borders. Advances in rail and shipping technology meant that people, goods, and disease could traverse the globe. Cholera, a diarrheal infection, is spread by food or water contaminated with the cholera bacterium, Vibrio cholerae (Centers for Disease Control and Prevention 2020). Cholera has a short incubation period, rapid course, and spreads best with the mass movement of large numbers of people (Rosen 2015, 158).

In the present frame of the novel, Florentino and Fermina are thrust into a barren and sickly landscape, as they venture along the water. Deforestation to feed the boilers of the riverboats and the senseless annihilation of the animal life have left a desolate world. In contrast to Florentino's memory of the river, from his single trip decades before, and Fermina's own imagination about the river, which position the Magdalena as the "father of waters," they are instead met with nothing but "the nauseating stench of corpses floating down the sea. For there were no more wars or epidemics, but the swollen bodies still floated by" (336). The whole world, not just their homeland, seems to be a diseased and rotting landscape. Throughout the novel, love and emotions are metaphorized as diseases, but by the end of the novel, the larger human population and project of modernity become an epidemic, leaving nothing but "the vast silence of the ravaged land" where "everything was gone" (337). However, like the poverty that remains in the background of Juvenal's life, the destruction of nature they encounter on the water remains a backdrop to the reunion trip of Fermina and Florentino.

Florentino is leading Fermina into the infected landscape of his own body, one, that, like the physical land they pass on the water, only promises contagion and sorrow. They travel alone, enjoying the emptiness of the boat until they dock and Fermina notices people boarding, people who attended to her after her husband's death. Because she "would 
rather die than be seen on a pleasure trip," Florentino and the captain conspire to "infect" Fermina through a type of metaphoric cholera. According to the captain, "The only thing that would allow them to bypass all that was a case of cholera on board" (342). Thus, Fermina must "contract" cholera. As Florentino and the Captain discuss preparations to "raise the yellow flag" (i.e. signal cholera on deck), the narrator reminds readers that cholera was still a viable reason for quarantine because "After all, everyone knew that the time of cholera had not ended despite all the joyful statistics from the health officials" (343). In the midst of Fermina's initiation into a metaphoric infection, the narrator's words remind the reader that perhaps Juvenal was more successful in creating an image and leaving behind a memory rather than actually improving the health of his homeland.

As Fermina and Florentino continue to sail under the cholera flag, which allows them to avoid picking up cargo or passengers, Fermina reflects that her return home is "going to be like dying" (346). Nearing their home, Fermina is struck by the same "pestilential stink" that greeted her husband so many years before when he returned from Paris (346). As with Juvenal, the stink of the bay reminds Fermina of "the horror of real life" (346). In the moment of her return, Fermina has two potential paths before her. The first is to be rid of the cholera that she "contracted" when the captain and Florentino decided to fly the plague flag. This choice, mandated by the Health Department, will require a period of quarantine to assure her body is free of cholera.

By quarantining herself and eradicating the cholera, even a metaphoric form, Fermina ensures a return to reality, the same reality that lifted the veil of illusion which colored her love for Florentino as a young girl. The second choice is to incubate the cholera; to stay aboard the ship and sail away. As with material forms of disease, in the end, Fermina is not given a choice. Instead, Florentino, who, in his relationship with her, has benefited from the deception inherent in illusion and memory, chooses to sail on "forever" (348). Despite Juvenal's best efforts to quell the cholera epidemic, Florentino has infected Fermina and taken her along for the "lunatic voyage" (345).

\section{Conclusion}

In a May 2020 Rodrigo García published an open letter in the New York Times to his late father, Gabriel García Márquez. In the letter, García described COVID-19 and how the epidemic has placed his father's works in a new light:

Not a day goes by that I don’t come across a reference to [García Márquez's] novel "Love in the Time of Cholera," or a riff on its title or to the insomnia pandemic in "One Hundred Years of Solitude." It's impossible not to speculate about what you would have made of all this. You were always fascinated with epidemics, real or of the literary imagination, as well as with things and people that return. (2020)

García's reflection helps to illustrate the way a novel like Love in the Time of Cholera has given readers new ways to frame and discuss a contemporary public health crisis like COVID19 especially as it relates to relationships and community. Besides renewed public engagement with Love in the Time of Cholera, García Márquez's novel has also become a staple in the numerous epidemic-focused health humanities syllabi and resources that have emerged across institutions to help educators teach about and in the era of COVID. ${ }^{4}$ Such academic and public trends further underscore the long overdue need for a public health humanities approach to García Márquez's novel. 
This paper makes the first published public health humanities interventions into Love in the Time of Cholera by focusing on the way public health issues, especially those related to epidemics and sanitation, shape the plot and metaphors of the novel. A public health humanities approach not only reveals new insight into the interaction between literature and health but also highlights the novel's critique of imperial health practices that is often overlooked in the extent medical humanities scholarship. This paper responds to assumptions in medical humanities scholarship about the scope and audience of a text like Love in the Time of Cholera; specifically, that texts about doctors are valuable for teaching medical students and physicians about medicine and their role as clinicians. The assumption that books about doctors can teach students how to practice good medicine often falls to the trap of over idealizing the doctor figure while neglecting that health and illness exist beyond the clinical setting. Love in the Time of Cholera, when read through the lens of public health humanities, raises questions about history, culture, attribution for behavior, power, and representation applicable to health and humanities disciplines alike. It also underscores the importance of recognizing that the health humanities is not the exclusive domain of physicians.

The output in this paper represents one of many possibilities for a public health humanities approach to García Márquez's novel. Further scholarship may benefit from a public health humanities readings that directly place Love in the Time of Cholera in conversation with COVID-19 media and texts. García Márquez's novel, which spans decades and details an epidemic, is particularly fertile ground for imagining and discussing public health in a post-COVID world.

Acknowledgements As with all writing, the work you are reading was shaped by so many brilliant and generous individuals. My gratitude to Professor Devan Stahl (who read and provided generous feedback on my manuscript as part of the American Society for Bioethics and the Humanities Early Career Advisor Program) and the peer reviewers and editors at Journal of Medical Humanities whose thoughtful feedback helped strengthen the ultimate goals of this paper. I also wish to thank my dissertation committee, Professors Laura Otis, Rosemarie Garland-Thomson, Valérie Loichot, and Sari Altschuler who helped me shape this research when it was part of my larger dissertation project. Finally, as always, all thanks to Jamie McGrath for putting up with the many iterations of this paper as it evolved from idea to article.

\section{Endnotes}

${ }^{1}$ My reading comes from Grossman's translation rather than the original Spanish edition. I note in my reading when I defer to the original Spanish.

${ }^{2}$ Public health humanities, first described by Lise Saffran (2014) is a branch of the larger health humanities which focuses on the interaction between the population-based social science of public health and humanities disciplines like literature. This paper deliberately proposes a public health huminites reading of Love in the Time of Cholera as extent health humanities scholarship on the novel retains a purely medical humanities focus.

${ }^{3}$ Attached to the theme of aging in this novel is a sub-theme of aging and gender. While men benefit from constant care from women throughout their lives (as sons and husbands), women are never the recipients of care, always the care givers (as wives and daughters). Urbino cannot conceive of a woman who can live life without a man in some capacity (i.e. as a care provider). Thus, women who outlive their husbands must spend the rest of their lives in grief. Although his wife proves him wrong, Urbino cannot imagine a woman who does not spend the rest of her days grieving the loss of her husband.

${ }^{4}$ Examples of the rich COVID-19 health humanities resources that have emerged from scholarly communities include Sari Altschuler and Elizabeth Maddock Dillon's crowd-sourced "Humanities COVID-19 Syllabus," https://cssh.northeastern.edu/english/2020/04/09/professors-sari-altschuler-and-elizabeth-maddock-dilloncompile-crowd-sourced-humanities-covid-19-syllabus/; Arden Hegele's curated "Epidemics in Historical Literature: Resources for Research, Practice, and Teaching," https://www.mhe.cuimc.columbia.edu/ourdivisions/division-ethics/covid-19-ethics-justice-resources/epidemics-historical-literature; and University of Pittsburgh Center for Bioethics \& Health Law, "COVID-19 Health Humanities Resources" http://bioethics. pitt.edu/HealthHumC19Resources. 


\section{References}

Centers for Disease Control and Prevention, National Center for Emerging and Zoonotic Infectious Diseases, and the Division of Foodborne, Waterborne, and Environmental Diseases. 2020. "Cholera Vibrio cholerae Infection General Information.” Accessed 10 November 2020. https://www.cdc.gov/ cholera/general/index.html\#one.

Clarkfield, Mark A. 2007. "Novel Medicine: Love in the Time of Cholera." Journal of the Royal Society of Medicine 100 (2): 107.

Ettling, John. 2000. The Germ of Laziness: Rockefeller Philanthropy and Public Health in the New South. Cambridge: Harvard University Press.

García Márquez, Gabriel and Edith Grossman (trans.). 2007. Love in the Time of Cholera. New York: Vintage.

García, Rodrigo. 2020. "A Letter to my Father, Gabriel García Márquez.” New York Times, May 6. Accessed 10 November 2020. https://www.nytimes.com/2020/05/06/opinion/coronavirus-garcia-marquez.html.

Jones, Anne Hudson. 1997. "Literature and Medicine: García Márquez' Love in the Time of Cholera." The Lancet 350:4.

La Berge, Ann Elizabeth Fowler. 2002. Mission and Method: The Early Nineteenth-Century French Public Health Movement. Cambridge University Press.

Palmer, Steven, and Iván Molina (eds). 2004. The Costa Rica Reader: History, Culture, Politics. Durham: Duke University Press.

“Popular Science.” 1909. Edgefield Advertiser, November 3. Accessed 10 November 2020. https://chroniclin gamerica.loc.gov/lccn/sn84026897/1909-11-03/ed-1/seq-9/.

Rosen, George. 2015. A History of Public Health. Revised Expanded Edition. Baltimore: Johns Hopkins University Press.

Saffran, Lise. 2014. “'Only connect': The Case for Public Health Humanities.” Medical Humanities 40 (2): $105-110$.

Soriano, Joan B. 2020. "Humanistic Epidemiology: Love in the Time of Cholera, COVID-19 and other Outbreaks." European Journal of Epidemiology 25:1-5.

"Strange Case of a Man who had Snakes in His Blood." 1900. The St. Louis Republic, 22 April 1900. Accessed 10 November 2020. https://chroniclingamerica.loc.gov/lccn/sn84020274/1900-04-22/ed-1/ seq-43/.

Toledo-Pereyra, Luis H. 2008. "Medicine, Gabriel García Márquez, and Love in the Time of Cholera." Journal of Investigative Surgery 21 (1): 5-8.

Publisher's Note Springer Nature remains neutral with regard to jurisdictional claims in published maps and institutional affiliations. 